\title{
Shunning Uncertainty: The Neglect of Learning Opportunities
}

\section{Citation}

Trautmann, Stefan T., and Richard Zeckhauser. 2011. Shunning Uncertainty: The Neglect of Learning Opportunities. HKS Faculty Research Working Paper Series RWP11-044, John F. Kennedy School of Government, Harvard University.

\section{Published Version}

http://web.hks.harvard.edu/publications/workingpapers/citation.aspx?Publd=8054

\section{Permanent link}

http://nrs.harvard.edu/urn-3:HUL.InstRepos:5347068

\section{Terms of Use}

This article was downloaded from Harvard University's DASH repository, and is made available under the terms and conditions applicable to Other Posted Material, as set forth at http:// nrs.harvard.edu/urn-3:HUL.InstRepos:dash.current.terms-of-use\#LAA

\section{Share Your Story}

The Harvard community has made this article openly available.

Please share how this access benefits you. Submit a story.

Accessibility 


\title{
Shunning Uncertainty: The Neglect of Learning Opportunities Faculty Research Working Paper Series
}

\author{
Stefan T. Trautmann
}

Tilburg University

Richard J. Zeckhauser

Harvard Kennedy School

\section{November 2011 RWP11-044}

\footnotetext{
The views expressed in the HKS Faculty Research Working Paper Series are those of the author(s) and do not necessarily reflect those of the John F. Kennedy School of Government or of Harvard University. Faculty Research Working Papers have not undergone formal review and approval. Such papers are included in this series to elicit feedback and to encourage debate on important public policy challenges. Copyright belongs to the author(s). Papers may be downloaded for personal use only.
} 


\title{
Shunning Uncertainty: The Neglect of Learning Opportunities
}

\author{
Stefan T. Trautmann \\ Tilburg University \\ PO Box 90153 \\ 5000 LE Tilburg, The Netherlands \\ s.t.trautmann@uvt.nl \\ Richard J. Zeckhauser* \\ Harvard University \\ Kennedy School of Government \\ 79 JFK St. \\ Cambridge, MA 02138 USA \\ richard_zeckhauser@harvard.edu
}

November, 2011

\begin{abstract}
Financial, managerial, and medical decisions often involve alternatives whose possible outcomes have uncertain probabilities. In contrast to alternatives whose probabilities are known, these uncertain alternatives offer the benefits of learning. In repeat-choice situations, such learning brings value. If probabilities appear favorable (unfavorable), a choice can be repeated (avoided). In a series of experiments involving bets on the colors of poker chips drawn from bags, decision makers often prove to be blind to the learning opportunities offered by uncertain probabilities. Such decision makers violate rational decision making and forgo significant expected payoffs when they shun uncertain alternatives in favor of risky ones. Worse, when information is revealed, many make choices contrary to learning. A range of factors explain these violations. The results indicate that priming with optimal strategies offers little improvement.
\end{abstract}

Keywords: risk; uncertainty; learning; information; gambler’s fallacy JEL codes: D81; D83; G11, C91

\footnotetext{
${ }^{*}$ Corresponding author. Harvard University, Kennedy School of Government, 79 JFK St., Cambridge, MA 02138 USA. Telephone: 1-617-495-1174; fax: 1-617-384-9340; email: richard_zeckhauser@harvard.edu
} 
Financial, managerial, and medical decisions often involve choice alternatives whose outcomes have uncertain probabilities. In contrast to alternatives with known probabilities, these uncertain alternatives offer the opportunity for learning in repeat choices. If the probability of a desirable outcome turns out low, the alternative can be avoided in future choices; if the probability turns out high, the alternative can be chosen again on future occasions. Thus if repetition is possible, the opportunity for learning brings value, making uncertain alternatives more valuable than known-risk alternatives of identical expected value on a single trial. To gather information regarding uncertain probabilities, people typically need to actively engage uncertain alternatives, something they are reluctant to do.

A range of theoretical analyses is based on the intuition of learning opportunities offered by uncertain alternatives. For instance, Grossman et al. (1977) show that, if learning is possible, consumers may buy a drug of unknown reliability, to gain information about its potentially beneficial effects. Mirman et al. (1993) find that a monopolist may set prices that deviate from the short term myopic optimal level, to collect information about the demand curve for its product. Rasmusen (2010) studies employee behavior if some tasks reveal their uncertain skills and other tasks do not. And Mueller and Scarsini (2002) show why risk averters should prefer uncertain over safe lotteries if learning is possible.

These studies clarify the benefits of uncertain alternatives in a range of applications. However, they do not speak to the question whether decision makers in the real world appreciate the benefits of learning opportunities offered by alternatives with uncertain probabilities, and therefore choose these alternatives to collect valuable information. Indeed, the empirical literature suggests that people often shun uncertain alternatives, forgoing significant benefits. Muthukrishnan et al. (2009) show that consumers prefer products from well established brands over cheaper products from less well-known brands, even when they consider them equally good in terms of quality. They find this effect for a large set of products, and find it most pronounced for people who avoid uncertain alternatives in a simple urn choice task. In a study of patients with chronic conditions, Frank and Zeckhauser (2007) find that primary care doctors treating depression tend not to respond to changes in patients symptoms when deciding whether to change medicines or dosages. Teodurescu and Erev (2011) discuss a wide range of situations e.g., negotiations with uncertain mutual benefits, and the treatment of chronic depression where people forgo the beneficial exploration of uncertain alternatives. 
We hypothesize that the neglect of learning opportunities offered by uncertain probabilities applies broadly, and that it will by strongly manifest in choices made under laboratory conditions. Because the above empirical observations can be driven by factors unrelated to the neglect of learning benefits, we conducted a set of controlled experiments that aimed to eliminate influences such as trust, accountability and liability, which often intrude on decisions outside the lab. The previous literature studying decisions with uncertain probabilities mainly focuses on violations of expected utility (Savage 1954) caused by the aversion to ambiguous and compound lotteries in one-shot situations (Ellsberg 1961; Halevy 2007; Kaivanto and Kroll 2011, Spears 2009). Learning benefits are not relevant to such choices.

Our analysis specifically allows for repeat choices and, therefore, for the opportunity for beneficial learning about uncertain alternatives. We find that blindness to learning opportunities under uncertainty is deeply rooted. Alternatives with uncertain probabilities are typically shunned in favor of options whose probabilities are known. . Our results suggest a range of explanations for subjects' violations of rational learning. We identify four categories of individuals who violate optimal learning: underestimators, minimum learners, insensitive stickers, and fallacious switchers. Those in the first two groups underestimate learning opportunities although they get the direction of inference correct. Insensitive stickers and fallacious switchers do worse when they make a second type of mistake: They make choices that are counter to what they have learned.

Several papers provide surprising results showing insufficient appreciation of learning and counterintuitive results regarding the processing of feedback for equilibrium play in simple games (Merlo and Schotter 1999; Rick and Weber 2010). The current paper has a different focus than these studies; it makes anticipation of learning an inherent part of the decision problem. Consistent with the previous literature, however, we also find that there is little transferability across tasks. For example, forcing subjects to learn in one context does not lead them to choose learning in another. Our paper is closest in spirit to those of Charness and Levin (2005) and Charness, Karni, and Levin (2007), who show that violations of Bayesian learning are most common where the simple behavioral rule of reinforcement learning gives different predictions than Bayes' rule. Those papers consider decision problems where all probabilities are known with certainty. We address the basic learning paradigm when some probabilities are uncertain. We observe that people's lack of a clear understanding of learning under uncertainty leads them 
to behave in a non-Bayesian manner. In this sense our paper shows that the violations identified for known risks apply more broadly under uncertainty, and often prevent people from choosing a position that would provide them with beneficial learning opportunities.

This paper reports on a series of experiments designed to test if subjects anticipate and properly appreciate the learning opportunities offered by uncertainty, and to tease out the various types of violations of rational learning behavior. Each experiment offers an uncertain option that provides for formal learning in a laboratory decision task. Moreover, the benefits of such learning are subject to mathematical calculation. We did not expect any such calculations by our subjects, but they do permit calculations of expected value, and the loss of such value if the learning option is not chosen. In Sections 1, 2, and 3, we present three incentivized lab experiments conducted with undergraduates at Tilburg University, the Netherlands. The experiments reveal both widespread shunning of options that provide learning benefits, and failures to learn in a rational fashion. We identify the four groups of violating subjects discussed above. Section 4 studies the limits of the learning violations and the transfer (or lack of transfer) of effective strategies across tasks. Section 5 discusses the implications of the results, and presents an extension of the current paradigm. Section 6 concludes.

\section{Experiment 1: Repeated Urn Choices}

\subsection{Design}

Ninety-nine undergraduate students participated in a laboratory experiment with real monetary incentives. To model a learning opportunity under uncertainty, we conducted a set of choice experiments utilizing two bags ${ }^{1}$, each with two colors of poker chips. In the baseline condition (BASE), we offered subjects a simple choice between a bet with known probabilities and an uncertain bet. Below, we often follow the terminology developed by Frank Knight (1921), where risky refers to bets with known probabilities, and uncertainty refers to bets whose probabilities are not known. The risky choice was to bet on the color of a chip drawn from a bag known to contain 5 red and 5 black chips. If the subject guessed the color correctly, she won

\footnotetext{
${ }^{1}$ In the experiments we used bags instead of urns. We will use the terms bag and urn interchangeably in the general description of choice situations. In some experiments, marbles were used instead of poker chips.
} 
$€ 10$; otherwise she won nothing. The uncertain choice was to bet on the color of a chip drawn from a bag with 10 chips, either red or black, with the numbers of each color unknown. Again, a correct guess won the subject $€ 10$, otherwise she won nothing.

Both bags were assembled by the subjects themselves, who filled the bags with chips from a box with 50 red and 50 black chips. Each subject first filled the known bag, and then, wearing a blindfold, put 10 chips into the uncertain bag. If not stated otherwise, this procedure was followed in all urn-choice tasks in this paper. This transparent two-stage compound procedure was chosen to minimize any suspicion, and to emphasize the expected symmetry of colors in the uncertain option. It follows from the design that, in this baseline one-shot decision, the expected winning probability equaled $50 \%$ for both the risky and the uncertain options, and the expected payoff from either option was thus $€ 5$. Note that given the equal numbers of the two colors in the box from which the uncertain bag was filled, and that draws were made without replacement, highly unbalanced distributions were quite unlikely.

To introduce the potential for learning in this setting, we included the following repeated urn-choice task (REPEAT), in which the subjects chose between betting twice on the color of a chip drawn from the bag with known composition or making the same bets with the uncertain bag. The task had two components, A and B. For A, the subject picked either the known or the unknown bag. She would have to stick with this bag for the rest of the experiment. For B, she had to bet on two successive trials on the color of a chip drawn at random from her chosen bag. On each trial, she was paid according to her prediction, as described above. After the first trial and before making her prediction for the second trial, the chip was replaced in the bag. In the play on the first trial, she automatically observed the color of a chip drawn from her chosen bag. The subject then played the second trial, making a new prediction. She could stick with her original color or switch to the other color, for another $€ 10$ prize. Thus, she could potentially adjust her bet according to the information gained from the first draw. The repeated, two-trial structure of component B was explained to the subjects and illustrated schematically by a time line before component $\mathrm{A}$ of the game was decided, that is before they had to choose between the known composition (risky) and unknown composition (uncertain) bags.

In the repeated game, for the risky bag the probability of winning is $50 \%$ for each draw. This is also true for the first draw from the uncertain bag. For the second draw from the uncertain bag, however, a subject can increase her chances of winning because she learned something from the first draw. For instance, the drawing of a red chip on the first trial would be recognized by a 
rational subject as indicating that red is now more likely. Specifically, by predicting the color drawn from the uncertain bag the first time as her second prediction, the subject will win 54.5\% on the second draw.

While in the BASE experiment both options are equally good from a Bayesian perspective, in the REPEAT game the expected value of the uncertain option is $€ 10.45$ versus $€ 10$ for the known option. A rational person might still pick the known option. She might make a trade-off between learning benefits offered by the uncertain bag, and other motives that led her to shy away from uncertainty (Ellsberg 1961; Halevy 2007; Kaivanto and Kroll 2011, Spears 2009). Thus, she may not choose the uncertain alternative even if she correctly understands learning. But if this is the case, increasing the relative benefit of the learning opportunity would make it more likely that the uncertain bag would be chosen.

In contrast, if a subject does not recognize the benefits of learning under uncertainty, increasing the relative benefit of learning opportunities would not affect her choice between the known and unknown bag. To discriminate between these two explanations, we employed a second two-trial treatment to see whether increased learning benefits made a difference. In treatment REPEAT4, the known bag contained exactly two red and two black chips, while the uncertain bag contained four chips, either red or black but in an unknown proportion. Otherwise the choice task was identical to the 10-chip, repeated, urn-choice task described above. Urns with fewer chips provide more significant learning, as going to the extreme case of a 1-chip urn makes clear. For the 4-chip case, the expected payoff from the known option is again $€ 10$, while for the uncertain option the expected payoff now equals $€ 11.20$, a $12 \%$ increase in expected payoff from correctly choosing on the second trial. ${ }^{2}$

\subsection{Results}

Table 1 shows the results. In the baseline one-shot treatment, we replicated the pattern found in previous studies where options with known probabilities are preferred to options with uncertain probabilities that offer the same expected value. Only 23\% of the subjects chose the uncertain option. No preference for the (strictly better) uncertain option was observed in the two-trial treatments offering learning. The uncertain option received less than $50 \%$ of the play in both the

\footnotetext{
${ }^{2}$ For the simple baseline game with no learning opportunities, it has been shown that the size of the urn (that is, the number of chips) does not affect behavior in one-shot choices between known and uncertain options (Pulford \& Colman 2008).
} 
REPEAT10 and REPEAT4 treatments. No difference between treatments was statistically significant $\left(\chi^{2}\right.$ tests, all $\mathrm{p}>0.10$ ). However, the uncertain bag was selected somewhat less often in the REPEAT4 than the REPEAT 10 treatment (29\% versus 39\%), although the learning value was 2 2/3 times greater (1.20 versus 0.45 ) in REPEAT4. This provides strong evidence that subjects do not properly recognize learning opportunities. One possible explanation is that it may be hard to recognize that the 4-chip situation offers more learning than the 10-chip situation.

Table 1. Choice of Uncertain Bet

\begin{tabular}{llll}
\hline \hline \multirow{2}{*}{$\mathrm{N}$} & $\mathrm{BASE}$ & REPEAT10 & REPEAT4 \\
\cline { 2 - 4 } Uncertain option chosen & 31 & 33 & 35 \\
binomial test, two-sided & $7(23 \%)$ & $13(39 \%)$ & $10(29 \%)$ \\
& $\mathrm{p}=0.003$ & $\mathrm{p}=0.296$ & $\mathrm{p}=0.017$ \\
\hline
\end{tabular}

Table 2 provides strong additional evidence regarding the neglect of the potential learning benefits from uncertainty. In this table, we show for the repeated-trial treatments the number of subjects who stayed with their first-trial prediction after either a successful or an unsuccessful prediction. Of the subjects who chose uncertainty, almost $40 \%$ behaved directly contrary to learning. To illustrate, many subjects (50\% for REPEAT10 and 40\% for REPEAT4) stuck with their initial prediction, despite choosing the color that did not get drawn on the first trial, which indicated that the other color was more likely to be drawn on the second trial. The behavior may either derive from a strong gambler's fallacy belief ("now red is due”), or may be caused by an insensitivity to learning, and by a decision to persist with a preferred color. We call these people insensitive stickers.

We also observed that many subjects (29\% in REPEAT10 and 40\% in REPEAT4) switched after an initial success, although such a success indicated their initial color was more likely on the second trial. We label these individuals fallacious switchers. They behave in accord with the gambler's fallacy. These two groups, the insensitive stickers and fallacious switchers, failed to capitalize on learning opportunities, indeed behaved directly contrary to them. They either drew wrong inferences, or drew no inferences from new information.

Table 2 also shows that subjects who chose the known option sometimes switched after an initial success, but almost never switched after an initial failure. That is, they deviated from 
purely random choice following some strategy. It seems that such proclivities played a role as well for subjects choosing the uncertain urn, despite violating optimal learning behavior. This can also be seen from the comparison of learning-compatible choices under uncertainty with "asif” learning-compatible choices with known risk. "As-if learning” (AIL) indicates a choice that would have been compatible with learning had the subject been playing the uncertain option. While there is no learning involved when the known option was chosen, its results allow us to identify choice patterns to compare with behavior when the uncertainty bag was selected. Pooling data from the 4-chip and the 10-chip games, we find no clear support of the hypothesis that uncertainty choosers make more learning-compatible choices than the known-risk choosers $\left(\chi^{2}\right.$ test, $\left.\mathrm{p}=0.145\right)$.

Table 2. Learning Behavior in Repeated-Bet Game

\begin{tabular}{|c|c|c|c|c|}
\hline & \multirow{2}{*}{ Option chosen } & \multicolumn{2}{|c|}{ Stayed with color predicted in stage 1} & \multirow{2}{*}{$\begin{array}{l}\text { Compatible } \\
\text { with learning }\end{array}$} \\
\hline & & First color right & First color wrong & \\
\hline \multirow{2}{*}{$\begin{array}{l}\text { 10-chip } \\
\text { repeated }\end{array}$} & Uncertain & 5/7 (71\%) & $3 / 6(50 \%)$ & $8 / 13(61 \%)$ \\
\hline & Known & 8/11 (73\%) & $9 / 9(100 \%)$ & $8 / 20(40 \%)^{\mathrm{AIL}}$ \\
\hline \multirow{2}{*}{$\begin{array}{l}\text { 4-chip } \\
\text { repeated }\end{array}$} & Uncertain & $3 / 5(60 \%)$ & $2 / 5(40 \%)$ & $6 / 10(60 \%)$ \\
\hline & Known & 10/14 (71\%) & $10 / 11(90 \%)$ & $11 / 25(44 \%)^{\mathrm{AIL}}$ \\
\hline
\end{tabular}

Note: AIL superscript indicates "as-if learning” for known-risk option indicates a choice that would have been compatible with learning had the subject played the uncertain option.

To our knowledge, there is no experimental evidence on repeated choices using a chance device between known risks and uncertain risks that offer learning opportunities. Yet, we believe that the potential to learn from uncertain situations is the norm in the world, albeit not with such artificial situations as drawing a ball from an urn. One frequently has a repeat choice of dry cleaners, driving routes, or restaurants, or strategies to employ when dealing with employees or friends. In each case, there will be available options where you are highly uncertain about outcomes, but it is logical to believe that what happens on first trial will correlate positively with the outcome on a second trial, implying the opportunity for learning. The driving route question is as follows: "You commute to work every day. There are two possible routes. Route A, your usual route, takes 30 minutes on average with a standard deviation of 3 minutes. You have only tried Route B three times. It has taken 28, 31, and 34 minutes. You expect to be commuting for 
many years. Should you stick with Route A, or try Route B a few more times? We have asked this question in many venues. Few individuals recognize the two-armed bandit feature of the problem, and the advantage of gathering information on Route B. ${ }^{3}$

We should note that some past experiments involving no learning possibility have shown a tilt toward uncertainty in repeated settings. Liu and Colman (2009) conducted experiments with repeated bets, each time with a newly assembled urn (hence no learning), and no switching opportunities. If the uncertain urn offers a larger prize and 100 repetitions are made, subjects prefer the uncertain urn, though they preferred the known urn on one trial. These authors argue that, through repetition, the uncertainty about the probabilities is reduced to a $50 \%$ chance as in the known-risk lottery, but with a higher prize.

Rode et al. (1999) studied the case in which at least $\mathrm{x}$ red balls have to be drawn in $\mathrm{n}$ trials. Indeed, they found that people correctly prefer uncertainty if $\mathrm{x}$ is large relative to expectation, implying that the known urn would give a low chance of achieving $\mathrm{x}$ successes, so that the uncertain urn would offer a higher expected payoff. We will present some data on this paradigm in section 5.

Our results on switching strategies replicate basic patterns observed by Charness and Levin (2005) in decisions that involve only known probabilities. Many subjects violate optimal switching strategies, and these violations do not diminish with the stronger learning potential in the 4-chip case (see their result 3, p.1305). In our setting, such learning violations indicate a much stronger bias against the favorable urn. 60 to 70 percent of our subjects chose the less favorable urn. In their study, a pure known-risk setting, only 20 to 30 percent of the subjects chose the less favorable urn.

\section{Experiment 2: Making Learning Opportunities Salient}

In Experiment 1, we identified an insensitivity to learning, reinforced by a strong type of gambler's fallacy. (Subjects choosing the known-risk option had no opportunity of falling into such error, since they learned nothing.) Furthermore, the learning behavior emerged

\footnotetext{
${ }^{3}$ Indeed, this advantage would persist even if Route B's average time to date were slightly greater.
} 
endogenously from observations of outcomes in the uncertain option, similar to the ways learning under uncertainty emerges in real world decisions. Possibly the participants merely overlooked the learning opportunity. While such obliviousness might apply in many real-world problems, we predicted that if the possibility for learning were made more salient, people might correctly perceive strong benefits from pursuing it. They would therefore predominantly choose the alternative with uncertain probabilities. To test this, we conducted an experiment in which people were forced to observe a sample before making their choices between known and uncertain options, and where we could identify learning also for those who chose the risky option.

\subsection{Design}

Forty-seven undergraduate students participated in an experiment that built on the BASE condition described in the previous section. The experiment consisted of two parts. Part II was identical to the 10-chip bag one-shot two-color bet for a prize of $€ 10$ in BASE: choose between the known and the unknown bag, and bet on the color of a chip once. In Part I, subjects had to draw one chip from the known bag and one chip from the uncertain bag, always with replacement. They noted the colors sampled, and then had to predict the contents of the two bags, that is, whether they expected more red or more black chips, or an equal number of red and black chips in each one. If the predicted compositions of both bags were correct, they would win $€ 10$. It was made clear to the subjects that exactly the same bags with the same contents that they had sampled in Part I would also be used in the BASE task in Part II where they had to choose one bag and bet on a color. At the end of the experiment, one of the two parts would be chosen by coin toss for real payment.

For the uncertain bag, sampling a red chip implied that the bag was more likely predominantly red than either predominantly black or equally distributed. For the known bag, the question was trivial because subjects knew that it contained equal numbers of red and black chips. The question was included for reasons of symmetry and to check basic understanding of the procedure. Indeed, all subjects correctly indicated the equal distribution in the known bag.

Sampling from the uncertain bag in Part I of the experiment forced the subjects to observe information about the distribution of colors, and allowed them to upgrade their expected 
likelihood of winning the prize for the Part II urn choice task. After sampling red, the probability of winning a bet on red increased to $54.5 \%$. The expected value of the ambiguous option was $€ 5.45$ versus $€ 5.00$ for the risky option, an increase of $9 \%$. Note that the benefit from learning was larger in this experiment than in the REPEAT task in experiment 1. In the repeated game, the subjects would still have to make the first bet without any information; hence, the proportional effect on total expected earnings would be smaller. Because all the subjects had to sample the uncertain bag and make a prediction regarding its contents, we could also observe learning errors for those choosing the known option.

\subsection{Results}

Table 3 shows the results. We found a similar level of uncertain urn choices as in the previous experiments, with $36 \%$ choosing uncertain ( $\mathrm{p}=0.079$, binomial test, two-sided). Overall, in the prediction of the contents of the uncertain urn, $26 \%$ violated learning and did not predict a majority of the color they drew. The incidence of this violation was similar among known-risk and uncertain-risk choosers. For uncertain urn choosers, we also observed whether they violated learning by betting adversely on the color not drawn in the sampling draw. We found that $24 \%$ committed such errors and that this group did not completely overlap with the group of people who failed the predominant color prediction in Part I of this experiment.

Table 3. Predicted Composition and Urn Choices after Forced Sample

\begin{tabular}{llcl}
\hline \hline & \multicolumn{3}{c}{ Part II Urn Choice } \\
\cline { 2 - 4 } & Known & Uncertain & All \\
\cline { 2 - 4 } $\begin{array}{l}\text { Urn Choice } \\
\text { Part I: violate learning in } \\
\text { prediction of bag composition }\end{array}$ & $7(23 \%)$ & $5(29 \%)^{*}$ & $12(26 \%)$ \\
$\begin{array}{l}\text { Part II: violate learning in color } \\
\text { prediction }\end{array}$ & - & $4(24 \%)^{*}$ & \\
$\begin{array}{l}\text { Total incidence of learning } \\
\text { mistakes }\end{array}$ & $7(23 \%)$ & $7(41 \%)$ & $14(30 \%)$ \\
\hline
\end{tabular}

Note: * These two groups had two members in common.

Among the 35 subjects who stated that they believed that the color they picked in Part I in the bag with uncertain composition was in the majority, 23 (roughly two thirds) then chose the risky 
bag in Part II. We asked these subjects why they had not chosen the uncertain option, and then bet on the color they believed predominated in the bag. Many argued that they had not perceived the sample as strong evidence for the color drawn and that they had predicted the majority composition more or less randomly. Since they had seen no clear evidence for either color, they had preferred the known option in the Part II bet. However, as the data show, it was still common for the subjects to predict the contents according to their samples. While those who correctly predicted the composition but then shunned the uncertain option might basically have had the right intuition, they underestimated the value of the sample.

Another group of subjects fall into the class we call minimum learners. They also announced the learning-compatible contents but then chose the known option. When asked about their decision, these subjects suggested a maximin way of thinking about probabilities: drawing a sample of a red chip was counted as evidence of one red chip versus no evidence for black at all. Such reasoning implied a correct majority prediction because there was more evidence for the red, and at the same time a preference for the known bet, because there were assuredly 5 red chips in the known option versus assurance of only 1 red chip in the uncertain option. ${ }^{4}$

\section{Experiment 3: Putting a Price Tag on Benefits from Learning}

Experiment 2 replicated the strong violations of learning that we found in Experiment 1. It suggested in addition that even those who do not commit such strong violations may still miss the clear learning potential offered by uncertain probabilities. To study how well people are calibrated when learning under uncertainty, we designed an experiment in which the subjects would not choose between known and uncertain bets. Rather, they would only make bets on uncertain options, some that offer learning and some that do not.

\footnotetext{
${ }^{4}$ The single draw of a red chip conveys considerable information about other possible combinations of bag contents. For example, the odds of 7 red chip and 3 black versus 3 red and 7 black, which were originally even, have now shifted to 7 to 3 .
} 


\subsection{Design}

Forty-three subjects participated in an experiment in which they had to predict the color of a marble drawn from an urn with 4 marbles, either red or black in an uncertain proportion. ${ }^{5}$ Without any sample, the probability of winning the prize in this bet equals $50 \%$. With a sample of one marble with replacement, predicting the color sampled increases the chance of winning to $61.73 \%$ and the expected value of the gamble by $23.47 \%$. The percentage benefit from learning is larger in this experiment than in the REPEAT4 condition with 4 chips in experiment 1 . In the repeated game, the subjects would still have to make the first bet without any information; therefore, the effect on the total expected earnings is smaller.

To measure the strength of the learning opportunities perceived by the subjects, we elicited a prize-equivalent for sampling as follows. Subjects could either bet on a color drawn from the uncertain 4-chip bag, without any sample, for a winning prize of $€ 20$ for a correct prediction, or bet on a color drawn from this bag, after sampling one chip with replacement, for a winning prize of $€ x$. There existed some $x<20$ such that the subject was indifferent about either directly betting for a prize of $€ 20$ or betting after learning something about the distribution of colors for the lower prize of $€ x$. We called this indifference value the lowest-acceptable prize (LAP) of the sampling opportunity.

We elicited the LAP using a Becker-DeGroot-Marschak (1963, BDM) mechanism. In a bag we placed 39 slips of paper with prize offers between $€ .50$ and $€ 19.50$ in equal steps of $€ .50$. Subjects wrote down their LAP. If the randomly selected offered prize "y" was equal or larger than the specified LAP, the subject would make a bet after sampling once for a prize of $€ \mathrm{y}$. If the offered prize " $y$ " was smaller than the LAP, the subject would directly predict the color of a chip, without sampling, for a prize of €20. After writing down their LAP, subjects also had to specify the color they wanted to predict in case they played without a sample for a prize of $€ 20$, and in case they played with sampling for a price of €y. In the latter case, they had to specify two predictions, conditional on the color sampled. That is, we elicited full betting strategies for all contingencies.

\footnotetext{
${ }^{5}$ Experiments 3 was conducted with marbles rather than chips. The marbles were drawn from a box containing 25 marbles of each color, instead of 50 of each, as in the previous experiments. Calculations account for the size of the box.
} 
Under expected payoff maximization, the optimal LAP was $€ 16.20$ because winning $€ 16.20$ with a $61.73 \%$ chance offers an expected value equal to winning $€ 20$ with a chance of $50 \%$, in the case of no sampling opportunity. ${ }^{6}$ The optimal strategy, obviously, involves betting on the color sampled.

\subsection{Results}

Based on the optimal LAP of $€ 16.20$, we defined people as well-calibrated learners if they specified a LAP between 14 and 18 inclusive. That is a range of two full euros below and above the optimal value, and it includes the prominent amount of $€ 15 .^{7}$ Thus, we applied a conservative criterion for learning neglect here. Table 4 shows the results.

Table 4. Valuation of Learning Opportunity

\begin{tabular}{|c|c|c|c|c|c|}
\hline & & $\begin{array}{l}\text { Well } \\
\text { calibrated } \\
14 \leq \text { LAP } \leq 18\end{array}$ & $\begin{array}{l}\text { Too hesitant to } \\
\text { take sample } \\
\text { (LAP>18) }\end{array}$ & $\begin{array}{l}\text { Too eager to } \\
\text { take sample } \\
(\mathrm{LAP}<14)\end{array}$ & All \\
\hline \multirow{2}{*}{ All } & Distribution by LAP & $20(47 \%)$ & $8(19 \%)$ & $15(35 \%)$ & 43 \\
\hline & Avg. LAP & $€ 15.73$ & $€ 19.38$ & $€ 9.07$ & $€ 14.08$ \\
\hline \multirow{2}{*}{$\begin{array}{l}\text { Correct } \\
\text { strategy }\end{array}$} & Distribution by LAP & $16(57 \%)$ & $5(18 \%)$ & $7(25 \%)$ & 28 \\
\hline & Avg. LAP & $€ 15.91$ & $€ 19.20$ & $€ 9.71$ & $€ 14.95$ \\
\hline \multirow{2}{*}{$\begin{array}{l}\text { Insensitive } \\
\text { stickers }\end{array}$} & Distribution by LAP & $2(25 \%)$ & $2(25 \%)$ & $4(50 \%)$ & 8 \\
\hline & Avg. LAP & $€ 15.00$ & $€ 20.00$ & $€ 9.50$ & $€ 13.50$ \\
\hline \multirow{2}{*}{$\begin{array}{l}\text { Fallacious } \\
\text { switchers }\end{array}$} & Distribution by LAP & $2(29 \%)$ & $1(14 \%)$ & $4(57 \%)$ & 7 \\
\hline & Avg. LAP & $€ 15.00$ & $€ 19.00$ & $€ 7.5$ & $€ 11.29$ \\
\hline
\end{tabular}

Note: Percentages refer to the distribution within the row

The first row shows the distribution of LAPs. Roughly half of the subjects were well-calibrated (LAP between 14 and 18); about one fifth were too hesitant to sample (LAP too high); and 35\% were too eager (LAP too low). Indeed, the average LAP in the too-eager group was below the expected value of the gamble assuming the sample led to a guess that was always correct. Note

\footnotetext{
${ }^{6}$ Risk aversion should lower a rational Bayesian subject's LAP below 16.2. A 50\% chance to win 20 euros is a mean-preserving spread of a $61.73 \%$ chance to win 16.20 euros, hence is more risky.

${ }^{7}$ Most people specified full euro amounts.
} 
that the LAP implies a comparison between an uncertain option with no sample and an uncertain option with a sample of one draw. In contrast, the previous experiments compared an uncertain option with a sample to known risk with 5 chances out of 10 . Subjects who held some maximin view might feel that they learned very little from one sample, but would find that far superior to no identifiable knowledge (uncertain urn with no sample). Thus, they strongly preferred the onedraw alternative and were too eager to reduce the uncertainty. In interpreting these results with the BDM mechanism, we issue a cautionary note. BDM is difficult for participants to understand, and the "overpayment” for learning may have come because individuals did not grasp how they should respond. ${ }^{8}$

The remaining rows of Table 4 distinguish subjects according to their betting strategies. Individuals who employed the correct learning strategy had a mean LAP about $€ 15$. They were well calibrated $57 \%$ of the time.

There were two groups who followed strategies contrary to the inference from the first draw: they bet against the color drawn. Thus, 8 of the 43 subjects (19\%) of the sample got the first draw wrong, but stuck with their color (insensitive stickers). 7 subjects (16\%) got the first draw correct, but then switched colors (fallacious switchers). Interestingly, both of these groups had lower average LAPs, respectively $€ 13.50$ and $€ 11.29$ than did those following correct strategy. Thus, they picked LAPs as if they were learning a lot, but then picked the wrong color. Both of these groups fell prey to the gambler's fallacy: assuming that a color had not come up the first time was more likely to come up on the second trial. Such choices are well documented for choices with known probabilities, as say with red and black on a roulette wheel. Here they are more disturbing, because they are going contrary to learning. Roughly two thirds (28 of 43) of subjects bet correctly. And $37 \%$ of subjects were both well-calibrated and followed optimal betting.

\footnotetext{
${ }^{8}$ On average, our participants were willing to accept 14.08 for the game with learning, as opposed to 16.20 , the actuarially fair value. They overpaid. -- We thank the referee for the observation about the BDM procedure.
} 


\section{Experiment 4: The Limits of Learning Neglect}

The previous experiments demonstrate various failures to anticipate learning under uncertainty when that uncertainty cannot be completely resolved. To examine the limiting conditions of this phenomenon, we considered two variations that we predicted would reduce the incidence of neglected learning benefits. First, we hypothesized that learning opportunities that eliminated all uncertainty would be taken by the subjects. Second, we predicted that experience in a learning task that revealed the general principle of learning under uncertainty would transfer to decisions in a task where learning was less obvious to people, the types of situations considered above.

\subsection{Design}

Thirty-two subjects participated in an experiment that had two parts. Each part involved monetary incentives and was presented as a separate experiment to the subjects. At the end of the experiment one part was randomly selected by a coin flip for real payment. The second part of the experiment was identical to the REPEAT4 repeated-urn choice experiment presented in Section 1. The first part of the experiment involved the following choice situation, modelled on the choice task in Charness and Levin (2005). Subjects were presented with one white bag and two indistinguishable blue bags. The white bag contained exactly one red and one black marble. One of the blue bags contained exactly two red marbles; the other blue bag contained exactly two black marbles. The subjects knew the possible contents of the two blue bags, but did not know which one contained only red and which contained only black marbles. Before learning about the decision problem, subjects chose one of the blue bags for the experiment, along with the white bag. The other blue bag was removed.

The decision problem was similar to the learning setting in Section 1. The subjects had to choose either the white bag with the known and equal distribution of red and black, or an uncertain blue bag containing only either two red marbles or two black marbles. The bag would be used to make a repeated bet on the color of a marble drawn, with replacement. Specifically, each subject first chose a bag, predicted a color, and then drew a marble; and the subject won $€ 5$ if the prediction was correct, and nothing otherwise. The marble was replaced in the bag, and the subject then again chose a bag, predicted a color, and drew a marble, winning another $€ 5$ if the 
prediction was correct. In this repeated betting situation, the chance of winning the prize equaled $50 \%$ for the known-risk white bag in both the first and the second drawings. For a blue bag, the first drawing also offered a 50\% chance of winning; the bag had been randomly selected with an equal chance of containing either two red or two black marbles, thus the winning probability was either $100 \%$ or $0 \%$. After betting on a color drawn from the blue bag in the first drawing, however, the subject learned the marble's color with certainty. That is, after the uncertainty of the first draw, the blue bag offered a certain gain of $€ 5$ in the second draw.

After the first part of the experiment was finished, the bags were set aside; then Part II, the repeated urn choice REPEAT4, was conducted exactly as described in Section 1. The goal was to see if the definitive learning situation with the blue bags would help subjects recognize the potential for valuable but imperfect learning with the uncertain bag.

\subsection{Results}

Table 5 shows the results. In the Part 1 repeated-betting task with complete resolution of uncertainty for the uncertain blue bag in the second drawing, $75 \%$ of the subjects chose the uncertain option ( $\mathrm{p}=0.007$, binomial test, two-sided). That is far superior to the previous experiments; the majority correctly understood the learning opportunity available for blue. Given the simplicity of the task, it is somewhat surprising that at least $25 \%$ of subjects did not see the benefit of the uncertain probability. ${ }^{9}$ However, we have observed serious learning failures before. The presence of this group of failed learners is consistent with the incidence of such learning deficits in our previous experiments, and also with the numbers observed in Charness and Levin's (2005) baseline condition, the basis for the design of the part 1 decision. The results show that the potential for complete resolution of uncertainty can reduce but hardly eliminate learning neglect. For subjects who intuited the basic advantage but underestimated the magnitude of learning, and for those who applied maximin learning, this task's structure immediately revealed that uncertain probabilities offer learning opportunities.

While $75 \%$ of subjects acted as if they identified the learning opportunity in Part 1 , the experience with Part 2 is disappointing. Only 31\% of subjects chose the uncertain option in the repeated 4-chip urn choice task REPEAT4 ( $\mathrm{p}=0.050$, binomial test, two-sided), despite their exposure to Part 1 . Indeed, the percentage of people choosing the uncertain option differed little

\footnotetext{
${ }^{9} 25 \%$ is a lower bound, since some who chose the blue bag may have done so at random.
} 
from that in Experiment 1. Clearly, the Part 1 experience failed to allow or alert subjects to understand the basic concept that securing information on an uncertain probability provides information. Most subjects who chose the known-risk option in Part 1 also chose the known risk in Part 2, as would be expected. However, 63\% of those who chose the uncertain option in Part 1 switched to the known option in Part 2. Thus, a majority of the subjects who appeared to get the right intuition in part 1 , did not successfully transfer their insights regarding learning opportunities to the Part 2 task.

Table 5. The Limits of Learning Neglect

\begin{tabular}{|c|c|c|c|c|c|c|}
\hline \multirow[t]{2}{*}{ Part 1: } & \multicolumn{2}{|c|}{$\begin{array}{l}\text { Known } \\
\text { (white: } 1 \text { red and } 1 \\
\text { black) }\end{array}$} & \multicolumn{2}{|c|}{$\begin{array}{l}\text { Unknown } \\
\text { (blue: either two red or } \\
\text { two black) }\end{array}$} & \multicolumn{2}{|l|}{ All } \\
\hline & $8(25 \%)$ & & 24 (75\%) & & 32 & \\
\hline \multirow[t]{2}{*}{ Part 2: } & Known & Unknown & Known & Unknown & Known & Unknown \\
\hline & $7(88 \%)^{*}$ & $1(12 \%)^{*}$ & $15(63 \%)^{*}$ & $9(27 \%)^{*}$ & $22(69 \%)^{*}$ & $10(31 \%)^{*}$ \\
\hline $\begin{array}{l}\text { Compatible } \\
\text { with learning } \\
\text { (within part 2) }^{\mathrm{a}}\end{array}$ & $1(14 \%)^{* *}$ & $1(100 \%)^{* *}$ & $4(26 \%)^{* *}$ & $9(100 \%)^{* *}$ & $5(23 \%)^{* *}$ & $10(100 \%)^{* *}$ \\
\hline
\end{tabular}

Notes: Part 1: Repeated bet with possible resolution of uncertainty. Part 2: Repeated 4-chip urn choice task REPEAT4. a: "As-if learning” for known-risk option: indicates a choice pattern that would have been compatible with learning had the subject played the unknown-risk option. * Probabilities conditional on Part 1 choice. ** Probabilities conditional on Part 1 and Part 2 choices.

Although the Part 1 experience did not prove sufficient to make most subjects recognize the benefits of uncertainty, it had some effects on behavior in the Part 2 decision problem REPEAT4. First, of those subjects who chose the unknown bag in Part 2, all made choices according to optimal learning, switching to/staying with the color drawn in the first trial (see bottom row of Table 5). In experiment 1 with no previous exposure to a statistical learning task, only $60 \%$ of subjects chose correctly in this fashion (Table 2). On the other hand, the Part 1 exposure seems to increase the incidence of gambler's fallacy for those who choose risky in Part 2. These risky-choosers learned nothing in Part 2 between the two trials. However, the "as-if learning” entry in the bottom row of Table 5 describes their switching behavior between trials and thus serves as a benchmark for the behavior of the subjects who chose the unknown bag in part 2 . Table 5 shows that only $23 \%$ of the risky choosers ( $\mathrm{p}=0.017$, binomial test, two-sided) switch as would be optimal had they chosen the uncertain bag. Because the index is below 50\%, 
it shows that subjects switch after success and stay after failures, as is predicted by the gambler's fallacy. Thus, while for some people the Part 1 task helps them to identify the optimal learning strategy, and to benefit from the uncertainty about probability, for a larger group of people it seems that Part 1 potentially added to their confusion about optimal learning, leading to widespread gambler’s fallacy behavior for the risky bag.

\section{Discussion}

In the real world, uncertain probabilities of success are often accompanied by a learning opportunity because they will have future choices whose outcomes will be correlated. If an innovative fast food restaurant proves successful in one neighborhood, it is much more likely to be successful in a second similar neighborhood. An employee who shows himself capable in one context is much more likely to be capable in another similar context. Real world decision makers do not seem to grasp the conceptual underpinnings of such learning opportunities. They often do not seem to anticipate the benefits of learning, and therefore do not choose alternatives with uncertain probabilities. They are likely to choose option A, which has a $60 \%$ chance of succeeding over option B, which has a one half chance of being at $90 \%$ but one half of being at $20 \%$. This makes sense when a choice is made once, since the probability of success is $60 \%$ rather than 55\%. But the decision maker should "pay for learning" and take the uncertain alternative given these values when there are two or more choices to be made. Failing to experiment in this way, they will not observe successful outcomes from uncertain alternatives. Thus, they will have no chance to benefit from learning.

We believe that most decision makers would properly interpret the observation of 4 successes and 1 failure as evidence of a high success probability if dealing with an uncertain 10 chip urn. However, our results strongly suggest that most people will not obtain helpful samples because, due to neglect or misconception of the mechanics of learning, they will shun uncertainty, settling on known alternatives that offer few or no learning opportunities. Examples where learning is not possible without an initial commitment to uncertain alternatives include scalable investments, new varieties of seed, or new medical treatments.

From an evolutionary perspective, if the benefits from learning are large, why would learning avoidance persist? This is a profound question. Fortunately, some research points to a 
potential direction for the search for an answer. Psychological findings suggest that negative experiences are crucial to learning, while good experiences have virtually no pedagogic power (Baumeister et al. 2001). This appears related to the finding that in individual decision situations, losses often weigh 2 to 3 times as much as gains (Tversky and Kahneman 1992, Abdellaoui et al. 2007, Table 1, p.1662). In the current setting, uncertain options would need to be sampled repeatedly in order to obtain a sufficient sample with few negative outcomes to determine whether to switch from the status quo. People require too much positive evidence before shifting to uncertain options. ${ }^{10}$

Other considerations, such as regret and blame avoidance, may also contribute to shunning uncertain alternatives. One does not know what returns would have come from an uncertain alternative. This reduces regret from not having chosen it. Blame from others also plays an important role. In principal-agent relationships, bad outcomes often lead to criticism, and possibly legal consequences because of responsibility and accountability. Therefore, agents, such as financial advisors or medical practitioners may experience a greater weighting of bad relative to good payoffs than do their principals (Eriksen and Kvaloy 2010a,b). Most people, for that reason, have had many fewer positive learning experiences with unknown alternatives than rational decision theory would prescribe.

Our results may complement our understanding of herding behavior and behavioral contagion in financial markets (Hirshleifer and Teoh 2009). In a recent experimental study, Goeree and Yariv (2006) brought subjects into a situation with uncertain probabilities similar to the ones studied in our paper, and then let them choose between an informative private signal, and an uninformative social signal. Specifically, subjects had to predict the contents of a jar that was filled with balls that were either predominantly red ( 7 red and 3 blue) or predominantly blue (7 blue and 3 red). The prior probability of either distribution was 50\%. Subjects could choose either of two pieces of information: (1) they could sample once with replacement from the jar before making their guess (informative statistical signal); or (2) they could choose to be told the predictions of 3 people who before them had randomly guessed the distribution without any statistical signal (uninformative social signal.). Across different conditions Goeree and Yariv

\footnotetext{
${ }^{10}$ We recognize this is not a complete explanation of the outcome from evolution. The question then becomes why we need negative outcomes to learn.
} 
find that between $34 \%$ and $51 \%$ of their subjects choose the uninformative social signal. They conclude that an intrinsic taste for conformity can explain their result.

If people correctly understood the benefits of learning, Goeree and Yariv's result would imply a strong preference for conformity. A study by Corazinni and Greiner (2007) using a simple risky choice paradigm instead of learning, questions whether such strong preferences for conformity exists. Our results suggest that even a weak preference for conformity may be enough in the Goeree and Yariv learning paradigm, thus reconciling their results with those of Corazinni and Greiner. We showed that most people have little concept of learning in situations where information is gained but uncertainty is not definitively resolved. These learning violators will not perceive the statistical sample as a valuable option, implying that mild curiosity or conformity would be enough to induce them to copy other people’s uninformed choice.

An interesting extension of the current paradigm concerns situations where uncertain alternatives are encountered repeatedly, and a success is needed on each trial to guarantee an overall success. Thus a proposal in an organization needs a signoff from four independent divisions before it can go forward, with an equal probability of success in each division. The traditional format proposal has a 70\% chance of approval from each division, implying an overall success rate of slightly less than 25\%. The new format being contemplated has an uncertain chance of success within each division. It could be $90 \%$ or it could be $40 \%$. Each is one half likely. Its overall success probability is $1 / 2\left(0.9^{4}+0.4^{4}\right)=33.6 \%$. Though the percentage for success at each division is lower, namely $(90+40) / 2=65 \%$, the overall probability of success has increased. This setting is quite different from the above learning paradigm. It is the positive correlation in the probability of success at each trial that offers the advantage.

Given the results of the current paper, we predicted that people would have difficulties understanding the benefits of uncertainty in this quite different repeated setting as well. We conducted an experiment using the bags filled according to experiment 1's REPEAT10 conditions. The subjects had to pick the known or unknown bag, and then pick one color that would apply for two draws with replacement. If both draws were of their color they won 10 euros, and otherwise nothing. The chances of winning were 25\% with the known urn, but 27.2\% with the unknown urn. Only 12 out 32 subjects choose the superior uncertain urn. The potential beneficial effects of uncertain probabilities when a series of successes is needed were missed. Uncertainty was shunned quite apart from the learning paradigm studied in this paper. 


\section{Conclusion}

Whether in financial, medical or other decisions, learning opportunities in which outcomes and probabilities are uncertain offer large gains over known risks. Many paths produce erroneous thinking about learning; the most prominent of them simply does not see the possibility. Indeed, an extreme learning experience - full resolution of a probability - in a similar setting proved to be an insufficient spur. The broad finding from diverse experiments is that individuals shun uncertainty and fail to recognize the benefits of learning that it offers. 


\section{References}

Abdellaoui, M., Bleichrodt, H., Paraschiv, C., 2007. Loss aversion under prospect theory: A parameter-free measurement. Manage Sci 53, 1659-1674.

Baumeister, R. F., Bratslavsky, E., Finkenauer, C., Vohs, K. D., 2001. Bad is stronger than good. Rev Gen Psychol 5, 323-370.

Becker, G. M., de Groot, M. H., Marschak, J., 1963. Stochastic models of choice behavior. Behav Sci 8, 41-55.

Charness, G., Karni, E., Levin, D., 2007. Individual and group decision making under risk: An experimental study of Bayesian updating and violations of first-order stochastic dominance. J Risk Uncertain 35, 129-148.

Charness, G., Levin, D., 2005. When Optimal Choices Feel Wrong: A Laboratory Study of Bayesian Updating, Complexity, and Affect. Am Econ Rev 95, 1300-1309.

Corazinni, L., Greiner, B., 2007. Herding, social preferences, and (non-)conformity. Econ Lett 97, 74-80.

Easley, D., O’Hara, M., 2009. Ambiguity and nonparticipation: The role of regulation. Rev Ellsberg, D., 1961. Risk, ambiguity, and the savage axioms. Q J Econ 7, 643-669.

Eriksen, K. W., Kvaloy, O., 2010a. Do financial advisors exhibit myopic loss aversion? Finan Mark Portf Manage 24, 159-170.

Eriksen, K. W., Kvaloy, O., 2010b. Myopic investment management. Rev Finance 14, 521-542.

Frank, R. G., Zeckhauser, R. J., 2007. Custom-made versus ready-to-wear treatments: Behavioral propensities in physicians' choices. $J$ Health Econ 26, 1101-1127.

Goeree, J. K., Yariv, L., 2006. Conformity in the lab. Working paper, Caltech.

Grossman, S. J., Kihlstrom, R. E. Mirman, L. J., 1977, A Bayesian Approach to the Production of Information and Learning by Doing. Rev Econ Studies 44, 533-547.

Halevy, Y., 2007. Ellsberg Revisited: an Experimental Study. Econometrica 75, 503-536.

Hirshleifer, D., Teoh, S. H., 2009. Thought and behavior contagion in capital markets, in: Hens, T., Schenk-Hoppe, K. R. (Eds.), Handbook of Financial Markets: Dynamics and Evolution. North-Holland/Elsevier, 1-46. 
Kaivanto, K., Kroll, E. B., 2011. Negative Recency, Randomization Device Choice, and Reduction of Compound Lotteries. Working paper, Lancaster.

Knight, F. H., 1921. Risk, Uncertainty, and Profit. University of Chicago Press, Chicago.

Liu, H.-H., Colman, A. M., 2009. Ambiguity aversion in the long run: Repeated decisions under risk and uncertainty. J Econ Psychol 30, 277-284.

Merlo, A., Schotter, A., 1999. A Surprise-Quiz View on Learning in Economic Experiments. Games Econ Behav 28, 25-54.

Mirman, L. J., Samuelson, L., Urbano, A., 1993. Monopoly Experimentation. Int Econ Rev 34, 549-563.

Mueller, A., Scarsini, M., 2002. Even risk averters may love risk. Theory Decis 52, 81-99.

Muthukrishnan, A. V., Wathieu, L., Xu, A. J., 2009. Ambiguity Aversion and Persistent Preference for Established Brands. Manage Sci 55, 1933-1941.

Pulford, B., Colman, A. M., 2008. Size doesn't really matter: Ambiguity aversion in Ellsberg urns with few balls. Exp Psychol 55, 31-37.

Rasmusen, E., 2010. Career concerns and ambiguity aversion. Econ Lett 108, 175-177.

Rick, S., Weber, R., 2010. Meaningful Learning and Transfer of Learning in Games Played Repeatedly Without Feedback. Games Econ Behav 68, 716-730.

Rode, C., Cosmides, L., Hell, W., Tooby, J., 1999. When and why do people avoid unknown probabilities? Testing some predictions from optimal foraging theory. Cognition 72, 269304.

Savage, L. J., 1954. The Foundations of Statistics. Wiley, New York.

Spears, D., 2009. Poverty and Probability: Reduction of Compound Lotteries in El Salvador. Working paper, Princeton.

Teodurescu, K., Erev, I., 2011. On the Decision to Explore New Alternatives. Working paper, Technion.

Tversky, A., Kahneman, D., 1992. Advances in prospect theory: Cumulative representation of uncertainty. J Risk Uncertain 5, 297-323. 